Авдеев Михаил Юрьевич

аспирант Технологического университета,

Московская обл., г. Королёв

\section{ТЕОРЕТИЧЕСКИЙ ОБЗОР СОВРЕМЕННЫХ ПОДХОДОВ К УПРАВЛЕНИЮ ПРОИЗВОДИТЕЛЬНОСТЬЮ ТРУДА}

Аннотация:

В отличие от большинства научных работ, посвященных проблеме управления производительностью труда и рассматривающих по сути один и тот же набор теоретических инструментов, в представленной статье, помимо научного анализа существующих подходов, выполнен поиск новых методов повышения производительности труда. Как правило, ученые предлагают решать проблемы повышения уровня производительности труда путем поиска скрытых ресурсов на предприятиях воздействия на работников, изменения корпоративной среды, при этом остаются без внимания производственные вопросы и вопросы организационно-экономического моделирования. Автором предпринята попытка восполнить существующий пробел. Помимо анализа особенностей каждой теории, научного обоснования необходимости формирования комплексного подхода, автор дополняет набор инструментов организационно-техническим (производственным) подходом. Также в статье обоснована эффективность, а в некоторых случаях - острая необходимость применения авторитарных методов в процессе управления предприятием. Комплекс теоретических подходов, рассмотренный $и$ дополненный автором, может успешно применяться в целях разработки методик для достижения устойчивого роста показателей производительности труда на российских предприятиях. Статья является частью маситабного научного исследования проблемы управления производительностью труда.

Ключевые слова:

производительность труда, управление производительностью труда, организационно-технический (производственный) подход, кадровый подход, социальный подход, авторитарный подход, психологический подход, мотивационный подход, организационно-экономическое моделирование, контроллине.
Avdeev Mikhail Yuryevich

PhD student, University of Technology, Moscow Region, Korolev

\section{A THEORETICAL REVIEW OF MODERN APPROACHES TO LABOR PRODUCTIVITY MANAGEMENT}

\begin{abstract}
Summary:
There are many studies on labor productivity management that deal with the same set of theoretical tools. This research analyzes the existing approaches in this regard and tries to find out the new methods to increase labor productivity. As a rule, scientists propose to improve labor productivity by searching for hidden resources in companies, influencing the employees, and changing the corporate environment. At the same time, production issues and organizational and economic modeling are overlooked. An attempt is made to fill this gap. In addition to the analysis of each theory, the scientific substantiation of the need to develop an integrated approach, the author complements the toolkit by an organizational and technical (production) approach. Besides, the research substantiates the efficiency of authoritarian methods and in some cases the urgent need to use them while managing a company. A range of theoretical approaches considered and supplemented by the author can be successfully applied to develop techniques for achieving sustainable growth of labor productivity indices in Russian companies. The paper is a part of a large-scale scientific study on the problem of labor productivity management.
\end{abstract}

Keywords: labor productivity, labor productivity management, organizational and technical (production) approach, personnel approach, social approach, authoritarian approach, psychological approach, motivational approach, organizational and economic modeling, controlling.

Проблеме производительности труда посвящено много работ отечественных ученых. Широкое освещение проблематики, безусловно, относится к положительным аспектам управленческой науки, так как на этой основе разрабатываются теории, позволяющие повысить эффеккивность систем управления. Однако при этом на многих предприятиях проблемы управления производительностью труда по-прежнему не решены, а в некоторых случаях требуется принятие срочных оперативных мер. Показатели производительности труда в настоящее время важны не только для специалистов и руководителей предприятий, но и для представителей высших органов государственной власти.

В предыдущих работах автором более детально обосновывалась теоретическая и практическая значимость рассматриваемой проблемы [1]. В настоящем исследовании производится научный анализ существующих теоретических подходов к управлению производительностью труда. Кроме того, предпринята попытка поиска новых инструментов повышения производительности труда, в чем заключается новизна работы. 
Недостатком многих предшествующих публикаций по заявленной проблеме выступает ограниченный характер рекомендаций по повышению уровня производительности труда: предлагается производить поиск скрытых ресурсов на предприятиях, воздействовать на работников, вносить изменения в корпоративную среду, тогда как вопросы производства, организационноэкономического моделирования оставлены без внимания. Частичному восполнению данного пробела посвящается данная статья.

В.Н. Войтова и А.Т. Замлелая выделяют следующие теоретические модели управления производительностью труда: механическую; системную; ориентированную на человеческие ресурсы; организации как общественного института [2]. Мы предлагаем выделять подходы согласно их значимости и уровню результативности. Также в работе представлена авторская точка зрения на подходы, использование которых зачастую игнорируется и недостаточно отражается в научных работах.

К эффективным организационным и экономическим подходам следует отнести организационно-технический (производственный), кадровый, социальный, авторитарный, психологический, мотивационный подходы и подход организационно-экономического моделирования результатов труда. Некоторые из вышеперечисленных подходов практически не применяются в производстве, что является неоправданным. Рассмотрим каждый из них подробнее.

Организационно-технический (производственный) подход предполагает, что управленческое воздействие на результаты производительности труда оказывается через организацию производства. Сущностью подхода является разработка организационно-экономических механизмов, устанавливающих правила построения, развития и обеспечения максимально возможного функционирования производственных систем [3]. Данный подход ранее не рассматривался как инструментарий воздействия на результаты производительности труда. Его изучение будет продолжено в следующих научных работах.

В работах некоторых ученых отмечается, что новые вызовы требуют не только развития новых теоретических подходов, но и создания инновационных концепций развития промышленности [4]. Таким образом, обосновывается значимость данного подхода, однако практически отсутствуют работы, которые изучали бы зависимость воздействия результатов деятельности в этой области менеджмента на показатели производительности труда.

Организация производства как наука взаимодействует с сопредельными сферами, целесообразно сюда также добавить взаимодействие с теориями управления производительностью труда. Главными принципами функционирования производственной системы являются синхронизация и интеграция всех производственных процессов. Надлежащее управление производственными системами может способствовать достижению высоких результатов в области производительности труда.

Существенное влияние на результаты производительности труда может оказывать кадровый подход. Низкие показатели производительности труда напрямую связаны с проблемами управления персоналом и вызваны несформированностью корпоративной культуры [5].

Сегодня основными задачами кадровых служб на предприятиях промышленности ошибочно считаются привлечение и удержание работников, тогда как вопросам устойчивости научных коллективов практически не уделяется внимания. Среди всего многообразия работ особую значимость для промышленности имеют единичные труды ученых-практиков, имевших опыт работы на промышленных предприятиях [6].

Приверженцы социального подхода считают, что ключевая роль в достижении высоких результатов производительности труда отводится социальным составляющим. Согласно мнению некоторых специалистов, результаты труда влияют на развитие общества и социальной системы в целом, в свою очередь показатели производительности труда напрямую зависят от набора социальных фракторов [7]. Данная точка зрения имеет право на существование, но построить эффективную систему улучшений, основываясь лишь на принципах социального подхода, в настоящее время не представляется возможным.

Предметом научной дискуссии является результативность применения авторитарного подхода к управлению производительностью труда. По утверждению И. Беха, его сущность заключается в наличии руководителя-тирана, единоличном принятии решений, развитой карательной мотивационной системе [8]. Позволим себе не согласиться с данным определением, как и с тем, что авторитарные методы в управлении являются недееспособными и безрезультативными.

Авторитарный подход следует понимать как жесткое регламентирование рабочих и производственных процессов, наличие принципа единоначалия, корпоративной культуры, в которой преобладает дисциплинированность работников, действия выполняются строго в соответствии с должностной инструкцией. Существует значительное количество успешных примеров применения данного подхода, по его правилам строятся взаимоотношения в войсковых соединениях. Директивный метод применяется на оборонных предприятиях. Оппонируя специалистам по поводу неприменимости принципа единоначалия, стоит отметить, что он не означает принятия решения только 
непосредственно руководителем, но предполагает безусловное подчинение работника своему начальнику. Принципы авторитаризма скрыто прослеживаются в системе менеджмента качества и других «лояльных» моделях управления. На практике существуют случаи, когда применение этого подхода жизненно необходимо. Например, к ним стоит отнести смену руководства предприятия в полном составе, после которой требуется как можно в более короткие сроки достигнуть необходимого уровня дисциплины и выработки со стороны каждого работника. Методы авторитарного подхода могут вполне обоснованно применяться в комплексной системе управления.

Более лояльным по отношению к работникам является мотивационный подход. Высокие результаты производительности труда достигаются путем поиска индивидуального подхода к каждому работнику. Под мотивацией чаще всего понимают влияние, оказываемое на человека в целях побуждения его к каким-либо действиям [9]. Отсутствие стабильности, неоднократные нарушения данных руководством обещаний, неоправданные надежды в конечном итоге приводят к тому, что мотивационные действия больше настораживают, чем обеспечивают положительный результат. Методы мотивации необходимо применять с особой осторожностью, предварительно изучив настроение работников в организации. С еще большим вниманием стоит относиться к западным моделям мотивирования персонала.

В некоторых источниках психологический подход носит название психофизиологического [10]. Его основными отличительными чертами являются управленческое воздействие, оказываемое на жизненную энергию работников, уровень интенсивности трудовой деятельности, фризические и психические нагрузки работников, обеспечение благоприятных условий на рабочем месте [11].

В работах авторов - приверженцев психологического подхода к управлению производительностью труда встречаются утверждения о том, что данный подход нацелен на заботу и получение благ исключительно работником [12]. В реальности же психофизиология выступает скрытым инструментом управленческого влияния. Опираясь на методики, разработанные психологами, менеджеры внедряют манипулятивные и схожие стили управления, которые ухудшают психологический климат организации и снижают производственные результаты. Несмотря на недостатки рассматриваемого подхода, целесообразно учитывать его положения при построении комплексной системы управления производительностью труда.

Наименее изученным в современной практике остается подход организационно-экономического моделирования. Цель исследований в области моделирования, по мнению А.И. Орлова, заключается в «разработке концепции, методологии и теоретических основ создания, изучения и применения системы организационно-экономических методов, позволяющих повысить эффективность процессов управления промышленными предприятиями и их объединениями» [13]. К основным задачам моделирования специалисты относят разработку организационно-экономических методов и моделей управления, классификацию и разработку систем инструментальных средств организационно-экономического моделирования [14]. Несмотря на наличие поддержки методик организационно-экономического моделирования [15], в научных кругах им уделяется недостаточно внимания. Наряду с организационно-экономическим моделированием в комплексной системе управления должны присутствовать методы контроллинга и управления жизненным циклом наукоемкого изделия [16].

Построение современной системы управления промышленным предприятием практически невозможно без выполнения следующих условий:

- избавление экономической теории от крена в сторону хрематистики (восприятия прибыли как главной цели деятельности);

- понимание того, что «экономика - наука о производстве, а не о прибыли», что основу экономической теории составляют экономика предприятия и инженерная экономика;

- подчинение рассмотрения экономических вопросов инженерной деятельности, организации производства [17].

Итак, в статье рассмотрены основные методы и подходы, наиболее часто предлагаемые современными учеными для построения эффективных систем управления производительностью труда. Подходы представлены в порядке убывания их значимости и уровня оказываемого влияния на результаты производительности труда. Данная градация предложена автором и отличает статью от работ других исследователей.

В перечне теорий по управлению производительностью труда автором впервые вводится понятие организационно-технического (производственного) подхода, что является приращением научного знания. Изучение этого подхода будет продолжено в следующих работах.

Отдельного внимания заслуживает взгляд автора на социальный и психологический подходы. Подавляющее большинство исследователей утверждают, что данные подходы реализуются исключительно во благо работника, тогда как, по нашему мнению, во многих случаях их применение может носить скрытый характер воздействия на работника и оказывать негативное влияние на состояние производительности труда на предприятии. 
Новизна публикации также определяется рекомендацией автора по использованию методов организационно-экономического моделирования и контроллинга.

Представленная научная статья является теоретической, однако результаты проведенного анализа, выводы и предложения могут быть использованы не только в теоретических целях, но и на практике, в деятельности предприятий реального сектора экономики.

\section{Ссылки:}

1. См., например: Авдеев М.Ю. Зарубежные подходы к управлению производительностью труда. Практический взгляд [Электронный ресурс] // Вектор экономики : электрон. науч. журн. 2019. № 4. URL: http://www.vectoreconomy.ru/images/publications/2019/4/economicsmanagement/Avdeev.pdf (дата обращения: 23.04.2019).

2. Войтова В.Н., Замлелая А.Т. Методы и модели управления производительностью труда: анализ мирового опыта // Российское предпринимательство. 2013. № 4 (226). С. 80-87.

3. Туровец О.Г., Родионова В.Н. Эволюция производственных систем в условиях становления инновационной экономики // Организатор производства. 2008. № 2 (37). С. 69-72.

4. Там же.

5. Агафонов А.Н. Актуальность применения методов контроллинга в системах управления персоналом // Инициативы XXI века. 2012. № 2. С. 89-91.

6. Агафонов А.Н. Указ. соч. ; Ларионов В.Г. Оценка персонала современной организации в рамках контроллинга // Контроллинг. 2011. № 41. С. 52-59 ; Хрусталев Е.Ю. Интеллектуальный потенциал и капитал российского обороннопромышленного комплекса: методологический аспект // Дайджест-финансы. 2012. № 2 (206). С. 11-18.

7. Фахрутдинова Е.В. Рынок труда в России и динамика его потребностей // Экономические науки. 2014. № 1 (110). С. $43-46$.

8. Бех І.Д. Особистісно зорієнтоване виховання - нова освітня фрілософрія // Педагогіка толерантності. 2001. № 1. С. 16-19.

9. Мотивация и стимулирование трудовой деятельности : учебник для студентов / под ред. А.Я. Кибанова. М., 2009. 524 с.

10. Хатхоху М.А. Социально-психологические аспекты организации труда на предприятии // Общество: социология, психология, педагогика. 2014. № 3. С. 14-15.

11. Вукович Г.Г. Качество рабочей силы: компетентностный подход // Экономика устойчивого развития. 2011. № 4 (8). C. $32-36$.

12. Хатхоху М.А. Указ. соч.

13. Орлов А.И. Организационно-экономическое моделирование при решении задач управления хозяйственными единицами [Электронный ресурс] // Политематический сетевой электронный научный журнал Кубанского государственного аграрного университета. 2013. № 87 (03). URL: http://ej.kubagro.ru/2013/03/pdf/53.pdf (дата обращения: 03.05.2019).

14. Там же.

15. Kutáč J., Janovská K. Podnikový controlling : učební text. Ostrava, 2012. 157 s.

16. Орлов А.И.: 1) Образование через науку: организационно-экономическое обеспечение решения задач управления [Электронный ресурc]. 2012. URL: http://www.bmstu.ru/ps/ orlov/blog/2012/10/obrazovanie-cherez-nauku-organizatsionnoekonomich/ (дата обращения: 03.05.2019) ; 2) Организационно-экономическое моделирование ...

17. Орлов А.И. Устойчивые математические методы и модели // Заводская лаборатория. 2010. Т. 76, № 3. С. 59-67 ; Hájek M., Mihola J. Analýza vlivu souhrnné produktivity faktorů na ekonomický růst České republiky // Politická ekonomie. 2009. Vol. 57, no. 6. P. 740-753.

\section{References:}

Agafonov, AN 2012, 'The Relevance of the Use of Controlling Methods in Personnel Management Systems', Initsiativy XXI veka, no. 2, pp. 89-91, (in Russian).

Avdeev, MYu 2019, 'Foreign Approaches to Labor Productivity Management. Practical View', Vektor ekonomiki: elektron. nauch. zhurn., no. 4, viewed 23 April 2019, <http://www.vectoreconomy.ru/images/publications/2019/4/economicsmanagement/Avdeev.pdf>, (in Russian).

Bekh, ID 2001, 'Personally Oriented Education - a New Educational Philosophy', Pedagogika tolerantnosti, no. 1, pp. 16-19, (in Ukrainian)

Fakhrutdinova, EV 2014, 'Labor Market in Russia and the Dynamics of the Needs', Ekonomicheskiye nauki, no. 1 (110), pp. 43-46, (in Russian).

Hájek, M \& Mihola, J 2009, 'Analýza vlivu souhrnné produktivity faktorů na ekonomický růst České republiky', Politická ekonomie, vol. 57, no. 6, pp. 740-753.

Khatkhokhu, MA 2014, 'Socio-Psychological Aspects of the Organization of Labor in the Enterprise', Obshchestvo: sotsiologiya, psikhologiya, pedagogika, no. 3, pp. 14-15, (in Russian).

Khrustalev, EYu 2012, 'Intellectual Potential and Capital of the Russian Defense-Industrial Complex: a Methodological Aspect', Daydzhest-finansy, no. 2 (206), pp. 11-18, (in Russian).

Kibanov, AYa (ed.) 2009, Motivation and Stimulation of Labor Activity: a Textbook for Students, Moscow, 524 p., (in Russian). Kutáč, J \& Janovská, K 2012, Podnikový controlling: učební text, Ostrava, 157 s.

Larionov, VG 2011, 'The Staff Evaluation of a Modern Organization in Controlling Framework', Kontrolling, no. 41, pp. 5259, (in Russian).

Orlov, Al 2010, 'Stable Mathematical Methods and Models', Zavodskaya laboratoriya, vol. 76, no. 3, pp. 59-67, (in Russian). Orlov, Al 2012, Education through Science: Organizational and Economic Support for Solving Management Problems, viewed 03 May 2019, <http://www.bmstu.ru/ps/ orlov/blog/2012/10/obrazovanie-cherez-nauku-organizatsionno-ekonomich/>, (in Russian).

Orlov, Al 2013, 'Organizational-Economic Modeling in Solving Problems of Managing Economic Units', Politematicheskiy setevoy elektronnyy nauchnyy zhurnal Kubanskogo gosudarstvennogo agrarnogo universiteta, no. 87 (03), viewed 03 May 2019 , <http://ej.kubagro.ru/2013/03/pdf/53.pdf>, (in Russian).

Turovets, OG \& Rodionova, VN 2008, 'The Evolution of Production Systems in the Conditions of the Formation of an Innovative Economy', Organizator proizvodstva, no. 2 (37), pp. 69-72, (in Russian).

Voitova, VN \& Zamlelaya, AT 2013, 'Methods and Models of Labor Productivity Management: Analysis of World Experience', Rossiyskoye predprinimatel'stvo, no. 4 (226), pp. 80-87, (in Russian).

Vukovich, GG 2011, 'The Quality of the Workforce: a Competence-based Approach', Ekonomika ustoychivogo razvitiya, no. 4 (8), pp. 32-36, (in Russian). 